\title{
DEPOIS DO CAPITALISMO, 0 GERENCIALISMO DEMOCRÁTICO
}

\author{
After capitalism, democratic managerialism \\ Después del capitalismo, el gerencialismo democrático
}

Luiz Carlos Bresser-Pereira1 | bresserpereira@gmail.com | ORCID: 0000-0001-8679-0557

${ }^{1}$ Fundação Getulio Vargas, Escola de Administração de Empresas de São Paulo, São Paulo, SP, Brasil

\section{RESUMO}

A partir do final dos anos 1970, o capitalismo experimentou uma fase regressiva - o capitalismo neoliberal financeirorentista - e, desde 2008, entrou em crise terminal. Os capitalistas deixaram de controlar o processo de acumulação de capital e inovação que os legitimava, e o capitalismo deixou de produzir desenvolvimento econômico e progresso humano. Em seu lugar, está surgindo uma nova organização social, que o autor denomina "gerencialismo democrático", no qual a classe dos gerentes ou tecnoburocratas voltou a se fortalecer e a constituir o núcleo da nova coalisão de classes dominantes. Ao mesmo tempo, a democracia vem enfrentando bem o desafio autoritário, e é possível prever que ela se aprofundará no gerencialismo democrático.

PALAVRAS-CHAVE | Capitalismo, neoliberalismo, gerencialismo, democracia, progresso humano.

\section{ABSTRACT}

Since the end of the 1970s, capitalism experienced a regressive phase - neoliberal rentier-financier capitalism - and, since 2008, has entered a terminal crisis. Capitalists ceased to control the process of capital accumulation and innovation that legitimized them, and capitalism stop to produce economic development and human progress. In its place, a new social organization is emerging that the author calls "democratic managerialism", in which the class of managers or technobureaucrats once again became stronger and constituted the nucleus of the new dominant class coalition. At the same time, democracy has been facing the authoritarian challenges well and it is possible to predict that it will deepen in democratic managerialism.

KEYWORDS / Capitalism, neoliberalism, gerencialism, democracy, human progress.

\section{RESUMEN}

Desde finales de la década de 1970, el capitalismo experimentó una fase regresiva - capitalismo neoliberal financierorentista - e, desde 2008, ha entrado en una crisis terminal. Los capitalistas dejaron de controlar el proceso de acumulación de capital e innovación que los legitimaba, y el capitalismo dejó de producir desarrollo económico y progreso humano. En su lugar, está emergiendo una nueva organización social que el autor denomina "gerencialismo democrático", en la que la clase de gerentes o tecnoburocratas nuevamente se fortaleció y constituyó el núcleo de la nueva coalición de clases dominante. Al mismo tiempo, la democracia ha enfrentado bien los desafíos autoritarios y es posible predecir que se profundizará en el gerencialismo democrático.

PALABRAS CLAVE I Capitalismo, neoliberalismo, gerencialismo, democracia, progreso humano. 
Há 60 anos, em maio de 1961, foi lançado o primeiro número da RAE. Dois anos antes, eu havia sido admitido por concurso na EAESP/FGV e escrevi, então, meu primeiro paper. Era uma tarefa que os membros da missão da Michigan State University davam aos novos professores antes que eles fossem para os Estados Unidos para fazerem seu MBA. Meu paper, escrito em inglês, "The rise of the middle-class and middle management in Brazil" (Bresser-Pereira, 1962), foi minha primeira incursão na questão do surgimento da nova classe gerencial ou tecnoburocrática, ao mesmo tempo que era uma análise do desvirtuamento das revoluções socialistas em direção ao estatismo. Meu ensaio devia ter sido publicado no primeiro número da $R A E$, mas seu primeiro editor, meu querido amigo e colega já falecido, Raimar Richers, apostou demais no método científico e entendeu que meu trabalho "não tinha base empírica suficiente". Estávamos em março de 1960, eu de partida para os Estados Unidos; chegando lá, submeti-o ao Journal of Inter-American Studies, que o publicou sem solicitar qualquer alteração. 0 tema da emergência de uma terceira classe no capitalismo foi muito discutido naquela época e teve seu grande momento com a publicação do grande livro de James K. Galbraith (1968), O novo estado industrial, no qual argumentou sobre o surgimento da "tecnoestrutura".

Os 18 meses que passei nos Estados Unidos foram de estudo intenso. Fiquei, então, impressionado com o desenvolvimento daquele país - não apenas o desenvolvimento econômico, mas também o desenvolvimento político. Naquele momento, os Estados Unidos eram o país mais rico e poderoso do mundo, e o padrão de vida de todas as classes não parava de aumentar; eram uma sociedade branca coesa que estava começando a enfrentar com firmeza o racismo e o sistema Apartheid; eram não apenas o exemplo de economia, mas também de democracia para o mundo. Eu e minha mulher, Vera Bresser-Pereira, tivemos oportunidade de assistir na TV aos famosos primeiros debates presidenciais, nos quais se enfrentaram John Kennedy e Richard Nixon; eram dois políticos brilhantes que, em seu debate, concordaram em tudo, mostrando o quão integrada era a sociedade americana naquele tempo.

O quadro, hoje, é muito diferente. Os Estados Unidos ainda são o país mais poderoso no plano econômico e militar, mas está perdendo sua hegemonia para a China. É um país preso a um liberalismo econômico ineficiente que, desde 1980, é a causa principal de taxas de crescimento muito baixas, de um enorme aumento da desigualdade e da estagnação do padrão de vida da metade mais pobre. É uma sociedade que perdeu coesão, que deixou de partilhar crenças e objetivos. Tem um sistema político em que a democracia se deteriorou e já não é mais exemplo para ninguém, em uma plutocracia que elege políticos sem real apoio popular e abriu oportunidade para que políticos populistas de direita pudessem se eleger presidentes - uma coisa inimaginável há 60 anos.

O que aconteceu neste tempo e levou os Estados Unidos a esta decadência? O fato histórico novo que levou o grande país e, com ele, boa parte do capitalismo rico à crise dos últimos 12 anos foi a Virada Neoliberal que ocorreu no Reino Unido e nos Estados Unidos em torno de 1980, com a eleição de Margareth Thatcher e Ronald Reagan para o comando desses dois países. Foi uma escolha errada do ponto de vista econômico; os Estados Unidos, que sempre foram um país desenvolvimentista (embora seus políticos fizessem um discurso liberal), que mantiveram tarifas aduaneiras altas até 1939 (a política industrial definidora de um regime de política econômica desenvolvimentista), de repente mudaram radicalmente de rumo e passaram a adotar um liberalismo econômico incompatível com seu próprio desenvolvimento econômico. Foi uma escolha errada no plano social, porque implicou aumento da desigualdade, e no plano político, porque significou a troca do republicanismo por um liberalismo político individualista.

Enquanto o liberalismo político vê a liberdade apenas como o direito do indivíduo de fazer aquilo que bem entender desde que não seja contra a lei, o republicanismo a vê como o objetivo a ser alcançado pela sociedade e como uma obrigação dos seus líderes políticos de defender o interesse público mesmo que ele contrarie seus 
próprios interesses. Essa era a visão da coisa pública que orientou os founding fathers no tempo da sua independência. Eles combinavam de maneira dialética duas ideologias opostas, o republicanismo e o e liberalismo. J. G. A. Pocock (1975) demonstrou esse fato em livro definitivo de 1975, The machiavellian moment. Esse republicanismo era ainda forte nos Estados Unidos de 1960 e moderava o liberalismo. Dou apenas dois exemplos relacionados com o Presidente John Kennedy: sua célebre frase, "Ask not what your country can do for you - ask what you can do for your country" - e o livro que publicou cinco anos antes de ser eleito presidente, quando era senador, Profiles on courage, no qual ele escolheu oito senadores para contar sua história, adotando como único critério de escolha ter cada um deles, em determinado momento de sua vida política, tido a grandeza de adotar a política que entendia consultar os interesses da nação americana, embora as forças políticas que o elegiam fossem contrárias a ela. Com a virada neoliberal, o republicanismo foi esquecido, e a sociedade americana ficou à mercê de um liberalismo econômico ineficiente e de um individualismo político reacionário.

\section{FASES DO CAPITALISMO}

Para entender o capitalismo, eu o divido em quatro fases segundo sua classe dirigente: Capitalismo dos Mercadores, Capitalismo dos Empresários, Capitalismo dos Gestores, e Capitalismo dos Rentistas e Financistas. Para fazer essa periodização, considero a Grã-Bretanha e a França, os dois países que passaram por todas essas fases.

A primeira fase, o Capitalismo dos Mercadores, cobre do século XVI a meados do XVIII e marca a transição do feudalismo para o capitalismo. Foi nessa fase que ocorreu a Revolução Capitalista - a formação do estado-nação e a revolução industrial naqueles dois países. A segunda fase, o Capitalismo dos Empresários, ocorreu entre o início do século XIX, quando a Revolução Industrial terminou na Inglaterra e na França, e a crise de 1929, que desmoralizou o liberalismo econômico; foi o capitalismo que Adam Smith e Marx analisaram, o primeiro saudando seu aparecimento e acentuando o papel do mercado na sua coordenação, o segundo o definindo como um modo de produção baseado na acumulação de capital com incorporação de progresso técnico e fazendo sua crítica.

Ainda nessa fase, no final do século XIX, acontece nos Estados Unidos a Segunda Revolução Industrial, que também denomino Revolução Organizacional, e começa a terceira fase - a do Capitalismo dos Gestores. Os gestores privados emergem nas grandes empresas privadas e, somados a uma também crescente burocracia pública, formam uma nova classe dos gestores ou classe tecnoburocrática. Os gestores passam, então, a substituir os empresários na administração das empresas. É a fase em que os Estados Unidos são o poder hegemônico, e o capitalismo deixa de ser liberal para ser desenvolvimentista ou keynesiano - passa a implicar uma intervenção moderada do Estado na economia. E passa também a ser social-democrático, porque nessa fase temos a construção do Estado do bem-estar social, principalmente na Europa. Foi, finalmente, a fase na qual o capitalismo viveu seu grande momento - os Anos Dourados do Capitalismo - um período de forte crescimento, estabilidade financeira e diminuição das desigualdades.

Não obstante esses bons resultados e o fato importante de que a classe gerencial estivesse longe de haver esgotado as contribuições que podia oferecer ao crescimento econômico, uma crise econômica moderada, nos anos 1970, envolvendo a queda da taxa de lucro e o surgimento nos Estados Unidos da estagflação, possibilitou a virada neoliberal. Temos, então, o Capitalismo dos Rentistas e dos Financistas ou Capitalismo Neoliberal, no qual os empresários são substituídos pelos rentistas, agora na propriedade das grandes empresas. 0 capitalismo retorna ao liberalismo econômico, enquanto sobem ao poder os "financistas", que, falando em nome dos 
rentistas, montam uma guerra não apenas contra a burocracia pública, mas também contra a classe gerencial privada. Os altos executivos privados não podiam ser expulsos da coalizão de classes porque dirigiam as grandes empresas, mas se tornaram os adversários prediletos dos stockholders. E os financistas são também gestores, geralmente com mestrados em Administração de Empresas (MBAs), senão com doutorados em Economia, que assumiram a gestão da riqueza dos rentistas e passaram a desempenhar o papel de intelectuais orgânicos do capitalismo neoliberal financeiro-rentista.

Para legitimar o liberalismo econômico, esses financistas recorrem à teoria econômica neoclássica - uma teoria econômica que voltou, a partir da virada neoliberal, a ser dominante nas universidades e pretende dar fundamento "científico" à ideologia neoliberal. Essa fase, ao excluir o Estado e tentar tornar o mercado a única instituição de coordenação econômica do capitalismo, se caracterizará por baixo crescimento, alta instabilidade financeira e brutal aumento da desigualdade. Por isso, de modo não surpreendente, ela termina cedo, com a grande crise financeira de 2008. Desde então, o liberalismo econômico está mais uma vez desmoralizado; as economias ricas crescem de maneira muito lenta, os bancos centrais emitem moeda para reduzir a taxa de juros que se torna negativa, caracterizando-se uma "estagnação secular”, e também para financiar a despesa pública durante a pandemia da Covid-19, sem que a demanda esquente e haja inflação. A partir da eleição de Donald Trump nos Estados Unidos e do referendo do Brexit no Reino Unido, os dois fatos ocorrendo em 2016, um populismo de direita surgiu como uma reação irracional ao fracasso do neoliberalismo, em especial sua incapacidade de enfrentar o problema do desemprego causado pela competição fracassada com a China. Como as três fases anteriores foram sempre "progressistas", no sentido de que levaram o capitalismo a avançar no plano do desenvolvimento econômico, social e político, e como o capitalismo neoliberal dos rentistas e financistas foi um período de grave retrocesso, talvez seja melhor não considerar essa uma verdadeira fase do desenvolvimento capitalista, mas um mero desvio reacionário.

\section{Uma construção humana}

No livro que estou escrevendo, Rentiers-Financiers' capitalism and after, critico os analistas de esquerda que não distinguem o neoliberalismo do capitalismo e rejeitam qualquer ideia de progresso no capitalismo, o criticam e preveem seu colapso iminente - ver, por exemplo, Dardot e Laval (2009). Um erro semelhante é dizer que o neoliberalismo é "a verdadeira face” do capitalismo e que os Anos Dourados teriam sido uma exceção. Esse é, por exemplo, o argumento adotado por Wolfgang Streeck (2011) quando afirma que "não são les trente glorieuses, mas a série de crises que se seguiram que representam o capitalismo democrático normal” (pp. 5-6). Essa visão faria sentido se entendêssemos o capitalismo como um fenômeno "natural", e não como resultado de uma construção social; se acreditássemos que os humanos nada mais foram do que joguetes em um processo histórico em que a vontade e a ação humanas estão ausentes. Essa é uma naturalização equivocada da história. Ignora que capitalismo é uma forma de sociedade regulada por duas grandes instituições - o Estado e o mercado - que, como todas as instituições, foram construídas pelos humanos. Pode-se dizer que essa construção é em parte

“inconsciente". De fato, Marx e Engels, com o materialismo histórico e o conceito de ideologia, deram uma contribuição importante para a compreensão das sociedades humanas e seu desenvolvimento. Mas, mesmo em sua época, e certamente ainda mais hoje, os humanos tinham objetivos políticos que eles incorporavam nas instituições - particularmente na maior delas, o Estado.

O Estado moderno é o sistema constitucional-legal e a organização dotada de poder coercitivo que o garante; é o principal instrumento de ação coletiva da nação. Pelo menos desde as três revoluções fundadoras 
do Estado moderno - a Revolução Gloriosa, a Revolução Americana e a Revolução Francesa - o Estado moderno é a instituição que surge com o capitalismo para definir e fazer cumprir os objetivos políticos finais (segurança, liberdade individual, melhoria dos padrões de vida, justiça social e proteção do meio ambiente), bem como os objetivos instrumentais (um estado-nação autônomo e democrático) que as sociedades modernas definiram para si próprias desde o século XVIII. O capitalismo foi o primeiro modo de produção a experimentar o desenvolvimento econômico e o "progresso humano", que defino como o processo histórico por meio do qual cada nação avança na realização desses objetivos. Assim, o capitalismo, hoje, não é uma forma natural de sociedade, mas uma organização social voltada formalmente para a realização desses objetivos políticos, é o primeiro modo de produção no qual houve desenvolvimento econômico e algum progresso humano. Um progresso limitado e insatisfatório, mas que não pode ser ignorado.

Os estados-nação hoje existentes são, portanto, o resultado da ação coletiva da nação para se criar uma sociedade política melhor. Nesse processo, os indivíduos e as organizações defendem seus próprios interesses como se fossem os interesses de todos, e, em consequência, as nações, muitas vezes, experimentam regressões históricas. Afinal, porém, o vetor dialético não só dos interesses de classe e dos acordos políticos, mas também dos princípios republicanos e solidários, que igualmente orientam a ação humana, resulta em progresso humano.

A seção anterior deste artigo é um resumo do primeiro capítulo do livro que estou escrevendo, Financiers-Rentiers' capitalism and after, no qual discuto o retrocesso econômico e político que o capitalismo neoliberal financeiro-rentista representou a partir de 1980, e mostro que, desde 2008, ele enfrenta uma crise terminal. Pergunto-me, então, o que se pode esperar em seguida, e minha resposta, no último capítulo, é otimista. Proponho que está surgindo uma nova forma de organização social que denomino "gerencialismo democrático". Antes de começar a escrever esse livro, eu era crítico dos que afirmavam que o capitalismo estava morrendo; o que está morrendo, eu dizia, é o capitalismo neoliberal. Revi, porém, essa posição quando me convenci de que a classe capitalista e o capitalismo haviam esgotado sua capacidade de promover o desenvolvimento econômico e, mais amplamente, o progresso humano e, afinal, vi surgirem pistas indicando a emergência de uma nova forma de organização social posterior ao capitalismo que denomino "gerencialismo democrático". Essa formação social não é uma fase do capitalismo, mas um novo modo de produção, que se configura quando a burguesia é substituída pela classe profissional no processo de acumulação de capital. A classe dominante será agora a classe gerencial pública e privada. Na nova coalizão de classes, a classe capitalista terá um papel secundário, na medida em que, a cada dia, se acelera a transferência do controle da acumulação de capital dos capitalistas para os gestores das grandes empresas privadas e as decisões de política econômica que estimulam ou desencorajam essa acumulação, para os políticos profissionais e servidores públicos.

A partir daqui, eu resumo o último capítulo desse livro. Argumento que o gerencialismo democrático que está surgindo será gerencialista porque a liderança no processo de investimento passou da classe capitalista para a gerencial; será democrático porque a democracia foi uma conquista histórica da classe trabalhadora e da classe média nos países capitalistas mais avançados na virada do século XIX para o XX e se tornou um regime político consolidado nesses países. Ao ser ameaçada, como vem sendo há 40 anos pelo neoliberalismo, que é autoritário, e mais recentemente pelo populismo de direita, mostra força e resistência, e assim se fortalece*. A democracia não apenas não está morrendo, mas prospera e será definidora da nova organização social. 0 gerencialismo democrático dificilmente será tão progressista nesta sua primeira fase como foram os Anos Dourados

* Defendi essa tese no ensaio publicado pela Lua Nova em 2020, "Não é a democracia que está morrendo. É o neoliberalismo que fracassou" (Bresser-Pereira, 2020). 
do Capitalismo, porque o problema da competição dos países em desenvolvimento não foi resolvido e continua a pressionar os salários nos países ricos. Mas, como prevejo que será desenvolvimentista, poderá levar os países mais avançados a voltarem a crescer e a aumentarem os padrões de vida.

\section{Democracia republicana, social e desenvolvimentista}

Quando Marx analisou o capitalismo, a nova classe capitalista compartilhava poder e privilégio com a aristocracia decadente. Para ele, essa seria a primeira e a última fase do desenvolvimento capitalista, porque logo a queda da taxa de lucro determinaria o colapso econômico, enquanto uma revolução socialista marcaria o fim do capitalismo. Em vez disso, o que aconteceu na virada do século XIX foram a Revolução Organizacional, que deu origem à nova classe gerencial, e, com o sufrágio universal, a Revolução Democrática, que deu algum poder ao povo para defender os seus interesses. Ele também não previu que, uma vez que a Revolução Industrial e capitalista fosse realizada por cada país, ela desencadearia um desenvolvimento econômico sustentado, o aumento dos padrões de vida e a mudança do fator estratégico de produção do capital para o conhecimento técnico e organizacional.

A lógica do surgimento de uma nova organização social está hoje ligada, por um lado, à demanda das sociedades modernas por progresso humano e, por outro, ao fato de que o avanço da democracia vem tornando 0 povo mais ouvido. 0 capitalismo tornou-se a forma dominante de organização de todas as sociedades modernas quando se revelou mais capaz de gerar riqueza e aumentar os padrões de vida do que o feudalismo e o escravismo, e, mais tarde, capaz de se adaptar ao surgimento da democracia. Mas foi sempre um modo de produção marcado pela desigualdade. Agora, após a virada neoliberal de 1980 e a crise de 2008 , quando a desigualdade econômica está atingindo novos máximos, o capitalismo não está se revelando capaz de gerar uma taxa de crescimento satisfatória, muito menos de reverter o processo neoliberal de concentração da renda, e mostra pouca capacidade de controlar as mudanças climáticas. Está, assim, se tornando evidente que o capitalismo esgotou sua capacidade de promover o progresso humano. Por outro lado, as elites capitalistas perderam o controle da acumulação de capital. Terceiro, a indignação não só da classe trabalhadora, mas também da classe média, com os maus resultados econômicos aumenta a cada dia os conflitos e a polarização política. Quarto, não está clara para os atores políticos qual será a saída, mas começam a surgir pistas de como será a nova organização social que nascerá dessa crise generalizada.

O capitalismo é um modo de produção dinâmico no qual uma coalizão de classes dominada pela classe capitalista comanda o processo de desenvolvimento econômico. Hoje, porém, os empresários capitalistas que ainda existem perderam força econômica e política. A solução para essa dificuldade, que venho discutindo comigo mesmo há algum tempo, é uma solução pós-capitalista. Tenho argumentado nesse livro que só poderíamos prever o fim do capitalismo se surgisse uma alternativa. O gerencialismo democrático pós-capitalista deverá ser essa alternativa. Deverá ser uma formação social gerencial porque a classe gerencial será a classe dominante; democrática porque um determinado tipo de administrador, o político profissional eleito democraticamente, terá sua legitimidade e poder político ampliados.

A democracia que resultou inicialmente da Revolução Democrática era uma democracia mínima (a garantia do Estado de Direito, dos direitos civis e do sufrágio universal), mas, desde então, a democracia estendeu-se também para os países de renda média, e a qualidade da democracia tendeu a melhorar. Nesse desenvolvimento econômico e político, a democracia transformou-se em um valor universal, não apenas em uma forma de governo, mas também em uma ideologia progressista. 
Hoje, a democracia é o único regime político dotado de legitimidade social. É instrumental para a realização dos objetivos políticos que as sociedades modernas definiram para si mesmas. No início do século XX, a primeira forma de democracia foi a democracia de elite ou democracia liberal; após a Segunda Guerra Mundial, principalmente na Europa, a democracia tornou-se republicana, social e desenvolvimentista; tornou-se republicana porque um número razoável de cidadãos e de políticos passou a agir de maneira cívica ao invés de liberal, porque deram prioridade ao interesse público ao invés de a seus interesses particulares, como supõe o individualismo liberal; tornou-se social, porque, além dos direitos civis e dos direitos políticos, os direitos socais passaram a ser considerados, e surgiu o Estado do bem-estar social; tornou-se desenvolvimentista ao invés de liberal, porque viu na intervenção moderada do Estado na economia um instrumento para o desenvolvimento econômico e o progresso humano em vez de ver o Estado como mero garantidor da propriedade e dos contratos. Embora a transição para uma democracia participativa caminhe lentamente nos países democráticos mais avançados, como a Dinamarca e a Suíça, minha previsão é que a democracia continuará a progredir porque a pressão da classe trabalhadora e das classes médias por mais participação política continuará a se aprofundar.

Nos últimos anos, enquanto o capitalismo neoliberal estava chegando ao fim, ele produziu o populismo de direita expresso, em 2016, na eleição de Donald Trump nos Estados Unidos e no referendo do Brexit na Grã-Bretanha. A reação da sociedade e das instituições democráticas a essa ameaça mostrou que a democracia é uma conquista definitiva da humanidade.

\section{Novos fatos históricos por trás do gerencialismo democrático}

Quais são os novos fatos históricos por trás do surgimento do gerencialismo democrático? Proponho quatro, dos quais o fracasso do capitalismo neoliberal é o primeiro e o mais óbvio. Os outros três são a incapacidade da classe rentista de controlar o processo de acumulação de capital e, de modo mais geral, sua incapacidade de governar; a ascensão da classe profissional cujas potencialidades não haviam ainda sido exauridas quando, em 1980, a virada neoliberal a desalojou da coalizão governante; e o fortalecimento da democracia, que, sob ameaça do neoliberalismo e, mais recentemente, do populismo de direita, mostra que é a grande conquista política da classe trabalhadora e das classes médias.

A pobreza ou a falta de capacidade de governança da coalizão de classes rentistas-financistas é nosso segundo novo fato histórico. Nas três fases anteriores do desenvolvimento capitalista (as fases mercantilista, industrial e gerencial), foi confirmada a previsão de Marx de que os detentores do capital manteriam o controle da sociedade assim que o país se tornasse totalmente capitalista. Nas três fases, os capitalistas (os comerciantes, os empresários e os administradores) não eram apenas aproveitadores privilegiados; eles desempenharam um papel de liderança no processo de produção. Eles não eram simplesmente pessoas ricas tornando-se cada vez mais ricas. Eram também uma espécie de delegados da sociedade encarregados de conduzir o processo de acumulação de capital e inovação, do qual depende o crescimento econômico. Foi seu papel fundamental no desenvolvimento capitalista que justificou e apoiou seu poder e riqueza. Não é o caso dos rentistas, que ou são recipientes ociosos de rendas associadas passivamente aos financiadores, ou são também especuladores financeiros. Não têm justificação para o seu poder e rendimentos, mas, como são os detentores do capital, continuam a ser a classe dominante. Essa, no entanto, não é uma condição sustentável, e é uma das explicações de por que o capitalismo dos rentistas-financistas neoliberais teve vida curta - prosperou apenas por 28 anos. É um argumento essencial por trás de minha afirmação de que, na nova forma de organização social que está 
crescendo, os detentores do capital não serão a classe dominante. Enquanto o capitalismo era o capitalismo dos empresários, os capitalistas eram centrais para o processo de desenvolvimento; perdeu parte de sua funcionalidade quando, no capitalismo dos gerentes, os gerentes substituíram os empreendedores na gestão das empresas privadas; e perdeu todo o apoio quando os capitalistas rentistas ociosos substituíram os empresários na propriedade das grandes empresas. Os rentistas e os financistas não estão comprometidos com o desenvolvimento econômico. Eles são uma classe capitalista ociosa interessada em dividendos de curto prazo, juros e aluguéis de imóveis, não na expansão de longo prazo das grandes empresas. A exceção são os terceiros membros da coalizão de classe neoliberal - os altos executivos que administram as empresas privadas. Mas, na nova organização social, desde sua primeira fase, eles terão o papel central no processo de acumulação de capital: no capitalismo neoliberal, suas ações são permanentemente travadas por rentistas e financistas.

Essa pobreza da coalizão de rentistas-financistas é crucial porque governar as sociedades modernas é uma tarefa extremamente difícil. Se o liberalismo econômico produzisse crescimento, governar os estados-nação seria uma tarefa relativamente simples. Os governos seriam obrigados apenas a garantir a ordem social e manter a conta fiscal equilibrada; o mercado cuidaria do resto. Mas sabemos que essa "mão invisível” não existe. A metáfora de Adam Smith da "mão invisível” só faz sentido quando não estamos nos referindo a todo o sistema econômico, mas apenas aos setores competitivos da economia. Os mercados não conseguem coordenar os setores não competitivos da economia, os cinco preços macroeconômicos, a conta corrente externa, a distribuição de renda, bem como a educação básica e a saúde; esses setores devem ser coordenados pelo estado, apesar das deficiências envolvidas. A afirmação neoliberal de que as falhas do Estado são piores do que as do mercado não se aplica, não porque esses setores envolvam falhas de mercado, mas porque o mercado está relativamente ausente, e faz mais sentido submetê-los à gestão pública. Os neoliberais rejeitam esse argumento porque esperam do mercado muito mais do que ele pode fazer. Eles esperam que o mercado coordene setores nos quais não há concorrência ou a concorrência existente é essencialmente enviesada, como é o caso dos cinco preços macroeconômicos. Governar os estados-nação, contribuir para o progresso humano e a paz mundial são as ações mais nobres que os humanos são chamados a praticar. Governar é uma tarefa muito difícil que requer políticos experientes e competentes, idealmente dotados de virtudes republicanas; políticos que continuamente reafirmam os principais valores e crenças da nação e são capazes de reinterpretá-los sempre que novos fatos históricos o exigirem. Poucos políticos têm essas qualidades. Eles podem ser progressistas ou conservadores, liberais ou desenvolvimentistas, mas devem ser republicanos e competentes politicamente.

Nosso terceiro novo fato histórico por trás da ascensão do gerencialismo democrático é o fato de que a classe gerencial não exauriu todas as suas potencialidades quando a virada neoliberal reduziu seu poder político. A ascensão de uma estreita coalizão de classes liberal financeiro-rentista interrompeu a emergência secular da classe gerencial, mas essa interrupção não foi nem podia ser definitiva. Enquanto, na fase neoliberal, os empresários capitalistas perdiam a centralidade, dois grupos gerenciais permaneceram associados aos rentistas - os financistas e os altos executivos das grandes empresas. Agora, no gerencialismo democrático que está surgindo, a classe profissional terá a oportunidade de liderar todo o sistema. Não apenas a classe gerencial privada, mas também a pública e, dentro dela, os políticos profissionais.

Finalmente, o quarto novo fato histórico que explica o gerencialismo democrático é a resiliência da democracia, à medida que sobreviveu e prosperou nos últimos 40 anos ao ser atacada pelo neoliberalismo, que é intrinsicamente meritocrático e autoritário, e, mais recentemente, pelo populismo autoritário de direita. Enquanto 
o liberalismo é uma ideologia capitalista que nasceu com o surgimento dos estados-nação e dos mercados nacionais, a democracia é uma ideologia e uma forma de governo apoiada na classe trabalhadora e na classe média, que a burguesia e o liberalismo rejeitaram por muito tempo com o argumento de que democracia seria a "tirania da maioria". A burguesia e o liberalismo eram a favor do Estado de direito e dos direitos civis, que são uma condição para a democracia, mas uma democracia minimamente definida só é alcançada quando a esses direitos se acrescenta o direito político básico - o sufrágio universal. A democracia foi uma conquista popular que, só depois de uma longa luta política dos partidos socialistas e dos intelectuais de classe média a favor do sufrágio universal, a burguesia aceitou. Foi necessário quase todo o século XIX para que a classe capitalista se sentisse relativamente segura de que a vitória dos partidos socialistas nas eleições gerais não levaria à sua expropriação e à instauração do socialismo. Aceitou a democracia, mas montou um amplo sistema de "salvaguardas" - leis que estabeleceram limites constitucionais rigorosos para a democracia: uma clara divisão de poderes e a exigência de maiorias qualificadas para alterar a Constituição. E limites práticos para o poder do povo: a possibilidade de financiar os políticos nas eleições, ou simplesmente suborná-los, o controle da mídia e a subordinação dos sindicatos a leis rígidas.

Mais adiante, mesmo as classes dominantes no capitalismo moderno - a classe capitalista e a classe gerencial - passaram também a ver a democracia como seu regime preferido, primeiro porque essas duas classes sociais são classes grandes e diversificadas cujos membros precisam de regras para regular suas ambições de alcançar poder político. Segundo, porque os governos autoritários são geralmente subordinados à classe capitalista, mas podem ser simplesmente governos arbitrários que não ignoram apenas os direitos do povo, mas também os direitos das elites.

\section{Sociedade de mercado sem classe dominante capitalista}

O gerencialismo democrático supõe uma sociedade de mercado sem classe dominante capitalista; supõe uma formação social em que continuamos a ter a propriedade privada dos meios de produção, os lucros e os salários são as duas receitas principais, e o estado e o mercado coordenam o sistema econômico. Não podemos, porém, chamar de capitalista esse tipo de formação social, porque a classe capitalista perdeu o controle do processo de acumulação de capital e inovação. Alguns dirão que é impossível pensar em uma sociedade onde o capital e o mercado estão presentes, mas a classe capitalista deixou de ser a classe dominante; ou onde a classe dominante anterior perdeu o poder, mas a nova formação social continua a receber o seu nome erroneamente. Existe, porém, um precedente histórico para esse tipo de situação. A aristocracia foi perdendo gradativamente seu papel militar durante o longo período em que a burguesia emergiu. Nesse processo histórico, chegamos ao mercantilismo, que já era uma primeira fase do capitalismo, mas continuava a ser visto como uma fase do ancien régime - o regime aristocrático das monarquias absolutas. Agora, após cerca de 100 anos de ascensão da classe gerencial, em que a burguesia perdeu gradativamente o controle do processo de acumulação de capital, temos dificuldade em ver o surgimento de uma nova organização social. Nas sociedades mais desenvolvidas, que são o objeto principal deste estudo, a ascensão da classe gerencial volta a ganhar força, a burguesia continua rica, mas perdeu sua função principal para altos executivos e servidores públicos eleitos e não eleitos.

Ao mesmo tempo, estamos vendo a democracia tornar-se mais forte, pois resistiu ao ataque dos neoliberais autoritários e agora está repelindo o ataque do populismo de direita. Nesse quadro, o povo e os setores mais cultos da classe média e os políticos estão ganhando influência política, e podem aproveitar esta oportu- 
nidade para fazer a democracia avançar, por um lado, tornando-a mais representativa das demandas populares, e, por outro lado, tornando o parlamento menos dependente dos interesses dos rentistas e financistas, e seus membros, mais comprometidos com uma política econômica de desenvolvimento responsável.

\section{CONCLUSÃO}

O gerencialismo democrático manterá muitas características do capitalismo - lucros e acumulação de capital, trabalho assalariado, coordenação de mercado de setores competitivos. A diferença fundamental é que a coordenação econômica da economia será feita de acordo não com a lógica do liberalismo econômico que fracassou, mas do desenvolvimentismo, que é a alternativa óbvia a esse liberalismo. Assim, assume-se que a classe gerencial dos gestores privados e funcionários públicos terá o papel estratégico de comandar o processo de acumulação e inovação do capital e, portanto, a tarefa de governar. Os políticos profissionais definirão as reformas econômicas e as políticas públicas exigidas como representantes do povo, dotados de maior responsabilidade e autonomia em relação aos ricos. Eles representarão os vários setores da sociedade, incluindo os setores capitalistas, mas não representarão principalmente a classe capitalista. Esses políticos trabalharão em uma série de reformas institucionais que tornarão suas candidaturas mais independentes do financiamento pelos capitalistas e gestores ricos.

Paul Mason (2013) diz que as sementes do pós-capitalismo estão começando a dar frutos. "O capitalismo não será abolido por técnicas de marcha forçada. Será abolido com a criação de algo mais dinâmico, quase invisível no antigo sistema, mas que irrompe, remodelando a economia em torno de novos valores, comportamentos e normas". Podemos ver, nas sociedades modernas, indícios que apontam na direção do novo. Mason acredita que eles apontam para "uma produção mais colaborativa; estão surgindo bens, serviços e organizações que não respondem mais aos ditames do mercado e da hierarquia gerencial”. Sim, o novo está surgindo das pistas deixadas pelo presente e pelo passado recente. Mas é preciso não ser tão otimista e acreditar que a revolução da informação esteja produzindo um "novo homem". o comportamento humano continuará sendo simplesmente o vetor dialético dos instintos de sobrevivência e de convivência humana. As sociedades não são apenas fruto do interesse próprio ou do instinto de sobrevivência, mas também da necessidade que cada um de nós tem de partilhar com o outro a vida em sociedade. Após 40 anos de neoliberalismo e individualismo, mudanças no comportamento individual e grupal em direção a um estilo de vida mais colaborativo e simples são necessárias; são uma resposta diante da ameaça da mudança climática e do aumento da desigualdade. A revolução da informação criou uma sociedade em rede, mas não uma sociedade melhor - uma sociedade em que o volume de informações aumentou caoticamente; em que as elites perderam o monopólio da informação organizada que o controle da grande mídia costumava assegurar. Ela abriu espaço para ideias novas e progressistas, mas também para teorias conspiratórias e notícias falsas produzidas na extrema-direita.

Minha aposta é que, no novo contexto produzido pela revolução da informação, o novo que está corporificado no gerencialismo democrático suplantará o antigo presente no neoliberalismo, no populismo de direita e nas teorias conspirativas. A mudança está acontecendo não em direção a uma sociedade ideal, mas a uma sociedade ao nosso alcance, onde o poder passa dos capitalistas rentistas para os gerentes, o poder político, principalmente, para os políticos profissionais. À medida que a democratização avança, o povo comum ganha não muita, mas um pouco mais de voz. Meu principal argumento apontando nessa direção foi o desgaste dos capita- 
listas, porque eles perderam seu papel estratégico de controlar o processo de acumulação de capital e inovação. Hoje, o gerente conduz a maior parte da acumulação de capital e das inovações dentro das grandes empresas. Dentro da classe capitalista, apenas os jovens empresários conservam um papel importante: comandar startups que, hoje, são a principal fonte de inovação radical. Mas essa é a única coisa que garante alguma legitimidade ao capitalismo e o mantém vivo; as outras coisas são apenas restos, a começar pela riqueza sem função social.

0 fracasso do capitalismo financista-rentista neoliberal foi uma nova evidência de quão errado estava o neoliberalismo ao assumir que os mercados são capazes de coordenar exclusivamente o sistema econômico, e abriu espaço para o retorno a um regime de política desenvolvimentista. Essa mudança já está começando a acontecer. Após a crise financeira de 2008, a ameaça representada pelo populismo de direita e a pandemia de Covid-19, estamos vendo os principais países se movendo em direção ao desenvolvimentismo. A Alemanha de Angela Merkel, a União Europeia e, finalmente, os Estados Unidos do presidente Joe Biden estão não apenas adotando grandes pacotes fiscais contracíclicos, mas também começando a definir e implementar políticas que promovam a reindustrialização. A expectativa de um livro publicado em 1985 por Evans, Rueschemeyer e Skocpol (1985) está se tornando realidade, o Estado está voltando a ser chamado para promover o desenvolvimento econômico. $\mathrm{Na}$ época em que o livro foi publicado, eles não foram ouvidos, mas a história fez com que a realidade e a necessidade prevalecessem sobre uma ideologia reacionária. A nova organização social não produzirá milagres, o que vem pela frente não é, de maneira alguma uma, utopia. Faço uma previsão otimista, mas que suponho ser realista. Estou apenas prevendo que estamos dando um passo em direção a uma forma mais razoável e equilibrada de coordenar a economia e governar os estados-nação.

\section{NOTA DO AUTOR}

Professor emérito da Fundação Getulio Vargas, Escola de Administração de Empresas de São Paulo.

\section{REFERÊNCIAS}

Bresser-Pereira, L. C. (1962). The rise of middle class and middle management in Brazil. Journal of Inter-American Studies, 4(3), 313-326. doi: 10.2307/164949.

Bresser-Pereira, L. C. (2020). A democracia não está morrendo. Foi o neoliberalismo que fracassou. Lua Nova - Revista de Cultura e Política, 111: 51-79. doi: 10.1590/0102-051079/111

Dardot, P., \& Laval, C. (2009). La nouvelle raison du monde: Essai sur la société néolibérale, Paris, France: La Découverte/Poche.

Evans, P. B., Rueschemeyer, D., \& Skocpcol, T. (Eds.). (1985). Bringing the state back. Cambridge: Cambridge University Press.
Galbraith, J. K. (1968). O novo estado industrial. Rio de Janeiro, RJ: Civilização Brasileira. Original em inglês, 1967.

Mason, Paul (2013) PostCapitalism - A Guide to Our Future", London: Penguin Books.

Pocock, J. G. A. (1975). The machiavellian moment. Princeton: Princeton University Press.

Streeck, W. (2011, Sept./Oct.). The crisis of democratic capitalism. New Left Review, 71, 5-30. Retrieved from https:// newleftreview.org/II/71/wolfgang-streeck-the-crises-ofdemocratic-capitalism

\section{CONTRIBUIÇÃO DO AUTOR}

Luiz Carlos Bresser-Pereira foi o único autor da construção teórica, de sua aplicação à realidade do capitalismo contemporâneo, e da redação deste artigo. Não houve levantamento especial de dados. Cecilia Heise se encarregou da revisão. 